\title{
Histopathological study and audit of the spleen in Nigerians
}

\author{
Kayode A. Adelusola ${ }^{1 *}$, Stephen A. Osasan ${ }^{1}$, Olusegun A. Afolabi ${ }^{2}$ \\ 1. Department of Morbid Anatomy \& Forensic Medicine; 2. Department of Community Medicine Obafemi Awolowo \\ University Ile-Ife, Nigeria
}

Author for correspondence Dr. K.A. Adelusola; Dept. of Morbid Anatomy \& Forensic Medicine, Obafemi Awolowo University, Ile-Ife, Nigeria. Email: kadelman02@yahoo.com

\section{SUMMARY}

\begin{abstract}
Studies on the spleen in Nigerians are rare. This study reviewed retrospectively the gross and histopathological findings in spleens received at the histopathology laboratory of the Obafemi Awolowo University Hospital (OAUTHC), Ile-Ife, Nigeria. 119 consecutive splenectomy specimens received within a period of 18 years were analysed with respect to age, sex, pathological diagnoses and indication for splenectomy. There were 76 males and 43 females with a mean age of 34.8 years (STD 19.6 years). Spleen weight, size, the presence of malarial parasite as well as fibrosis was not documented in many cases. The most frequent finding both grossly and microscopically was haemorrhagic necrosis from laceration of the spleen arising from trauma (62.7\% of all cases). Road traffic accident (RTA) accounted for $86 \%$ of all trauma cases and was the predominant finding in both sexes up to the age of 50 years. Thereafter, haematological malignancy was the predominant finding in the spleen. Chronic lymphocytic leukaemia (CLL) was the most common haematological malignancy in the spleen. The indications for splenectomy correlated well with the histological findings (kappa=0.81). Pathological description of spleen specimens is inadequate. Trauma is the major reason for splenectomy. In elderly Nigerians, splenectomy specimen would likely show CLL.
\end{abstract}

(Afr J Health Sci. 2007; Vol 14:195-200)

\section{Introduction}

The spleen is the largest organ of the mononuclear phagocyte system and is involved in all systemic inflammation, generalised haematopoietic disorders as well as metabolic disturbances [1]. Upon antigenic stimulation, splenic follicles enlarge and develop germinal centres, similar to reactive follicular hyperplasia in lymph nodes. The location of the spleen in the abdomen where it is not protected by a bony cage makes it very prone to traumatic injury. The resulting haemoperitoneum and haemodynamic disturbances in some cases may necessitate a splenectomy [2].

Primary diseases of the spleen are not common. However, the spleen is often involved as part of a component of processes affecting many tissues in the body, especially haematologic malignancies [3-4]. In many of these diseases the spleen is enlarged. A massively enlarged spleen is a burden to the individual and carries the risk of rupture with the slightest physical assault. In the tropics, acute malaria infection is a cause of splenic enlargement. Chronic malaria spleen is dark greyish, often with evidence of perisplenitis and trabecular fibrosis. Individuals without spleen in malaria endemic areas carry the risk of developing cerebral malaria, and consequently have to be on anti-malaria prophylaxis for life. The spleen is a neglected area in terms of research. Consequently there is the risk of underreporting both the gross and microscopic changes in the organ by pathologists. This paper therefore is a study on spleen specimens with a view to auditing the gross and microscopic description and analysing the pathological findings in splenectomy specimens with respect to gender and age.

\section{Materials and Methods}

All splenic tissue (splenectomy) specimens sent to the histopathology department of the Obafemi Awolowo University, Ile-Ife, Nigeria between 1988 and 2005 (18 years) formed the basis of this study. All were complete splenectomy specimens removed by open laparotomy. The spleens were received already fixed in $10 \%$ neutral-buffered formalin. Spleens were sectioned serially by bread loafing and re-fixed in $10 \%$ formol saline for 24 to 48 hours before sectioning and processing. In addition to haematoxylin and eosin, stains such as Giemsa, Perl's Prussian blue and Periodic Acid Schiff were used when necessary to make a conclusive opinion. The indications for splenectomies were noted. Also noted 
were the weight, size and the pathological description in respect of presence of malaria parasite and trabecular fibrosis. Pathological diagnoses were analysed with respect to age and sex. Statistical analysis was performed for differences in proportions, using Chi square ( $\mathrm{p}$ is significant at $<0.05$ ) by SPSS version 12 .

\section{Results}

One hundred and twenty three (123) spleen samples were received during the period of study. 119 had adequate data to be included in this study. There were 76 males and 43 females. The age range was 1 year to 86 years (mean 34.8, STD 19.6). Fig. 1 shows the number of cases of splenectomy with age and sex. The highest number of splenectomy was in the age groups 11-20 and 21-30 years (22 cases each). Males predominated in the age group 11-20 (16 males, 6 females). The incidence declined after the age of 60 years.

Fig. 1: Number of cases of splenectomy with age and sex

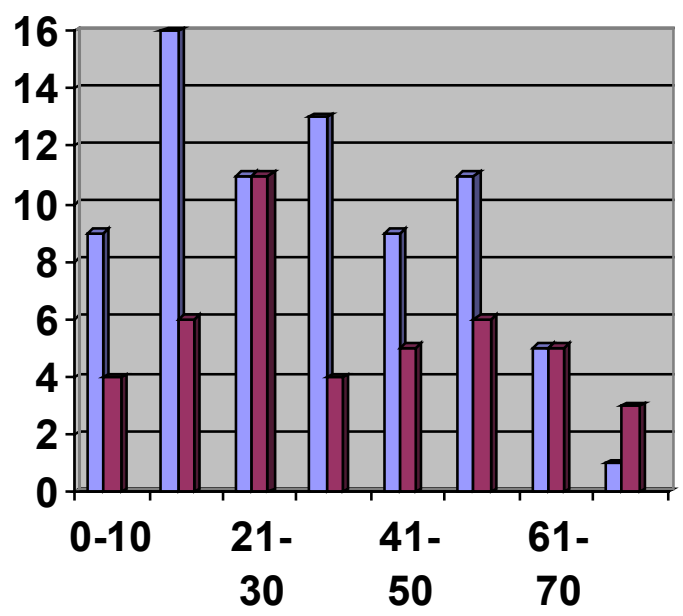

Table 1 shows the age distribution of the various histological diagnoses. Haemorrhagic necrosis from trauma was the most common histological finding overall $(n=74)$. Of these, 64 cases were from RTA (86\%), 6 from gunshot wounds and 2 each from fall from heights and blunt abdominal trauma. The next most common finding was haematological malignancies (HM; $\mathrm{n}=19)$. It included chronic lymphocytic leukaemia (CLL; $n=11)$, non-Hodgkin's lymphoma $(n=4)$, Hodgkin's lymphoma $(n=2)$ and 1 case each of essential thrombocytopaenia and Waldenstrom's macroglobulinaemia. The peak age incidence for haematological malignancies was 51-60 years. There was a significant association between
Only 32 spleens $(26.9 \%)$ had their weight recorded. Nine of these were spleens involved with haematological malignancies and they had the highest mean weight of $2289 \mathrm{gm}$. Spleen size was measured in 85 cases. Again spleens with HM had the highest size (recorded in 17 cases), ranging from $11 \times 6 \times 5 \mathrm{~cm}$ to $29 \times 20 \times 10 \mathrm{~cm}$. Fig. 2 shows the gross appearance of a case of splenic rupture from RTA. There is evidence of perisplenitis on the capsular surface. Cut surface of the spleen shows areas of haemorrhage and necrosis (Fig.3). Microscopically some of the spleens in this study showed trabecular fibrosis, and in some cases areas of old haemorrhage. There were cases with haemozoin pigment within macrophages, but the unequivocal presence of malaria parasite was not mentioned in any of the reports. Involvement by solid tumours was mainly located centrally, with small satellite lesions peripherally. The correlation between indication for splenectomy and histopathology diagnosis was good $(\mathrm{p}=0.005 ; \mathrm{kappa}=0.81)$.

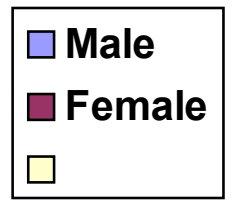

age and histological diagnosis $\left(\mathrm{p}=0.001, \mathrm{Chi}^{2}=\right.$ $50.72, \mathrm{p}$ is significant at $>0.05)$. All the 3 malignancies of other sites (MOS) were from the GIT and they consisted of 2 gastric cancers and 1 gastrointestinal stromal tumour (GIST). Diseases classified as others $(n=13)$ are: splenomegaly of unknown cause, that is, spleen showing follicular hyperplasia only on histology with no obvious underlying cause $(n=10)$, one case each of lipidosis, congestive splenomegaly, and Gandi-Gamna bodies in a 55 -year old man with massive splenomegaly without clinical or laboratory evidence of sickle cell disease or congestive heart failure. 
Fig 2: Splenic rupture from road traffic accident. There is a vertical laceration on the diaphragmatic surface as well as the area of splenitis on the left and haemorrhage on the right.

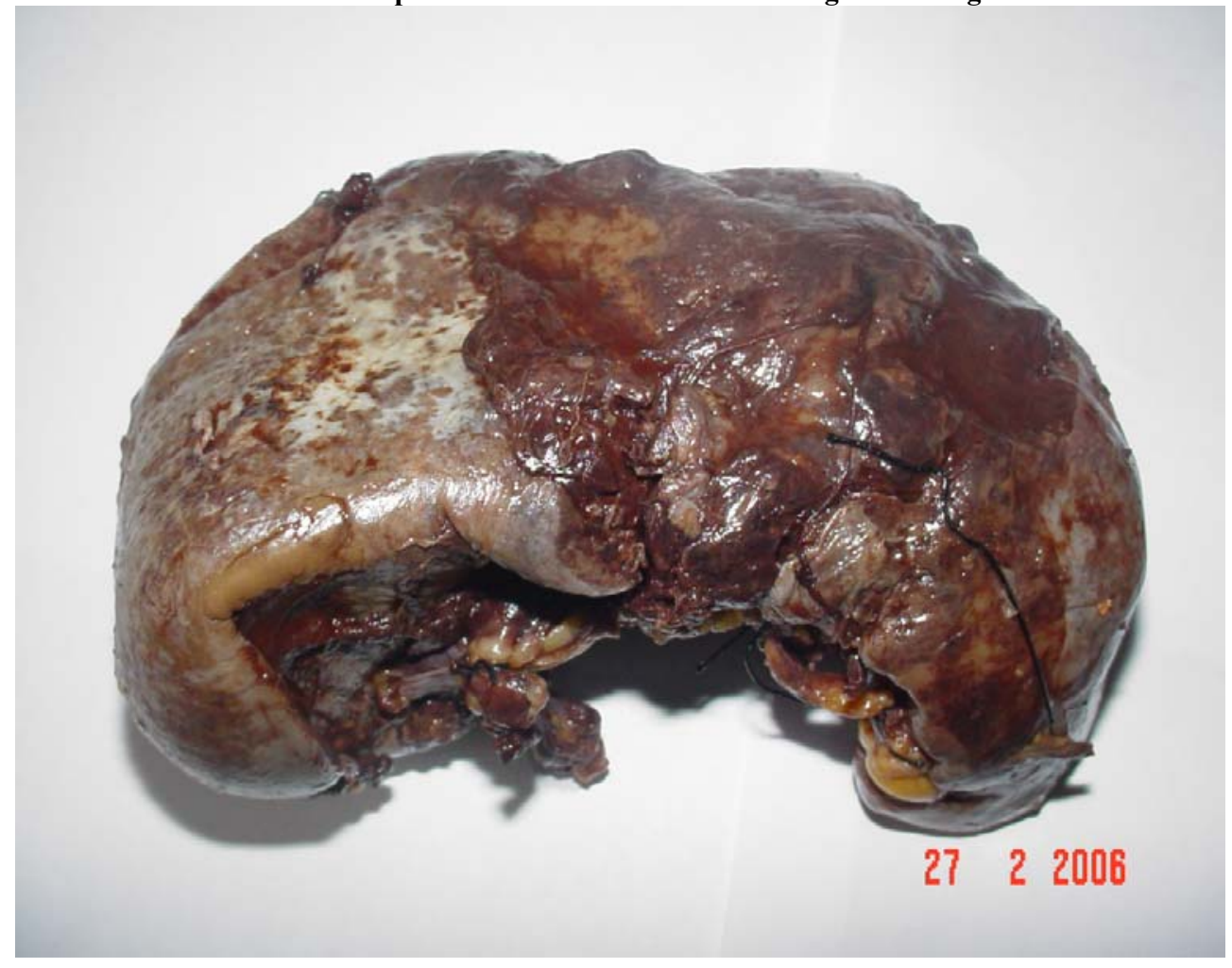

Table 1.Age distribution of the histological diagnoses

\begin{tabular}{|lcccccccc|}
\hline Diagnosis & & \multicolumn{1}{l}{} & & & & \\
\hline Age & Trauma & HM & SCD & MOS & ITSS & Infection & Others & Total \\
\hline $0-10$ & 9 & 2 & 1 & - & - & - & 1 & 13 \\
\hline $11-20$ & 16 & - & 2 & - & - & 2 & 2 & 22 \\
\hline $21-30$ & 18 & - & 1 & - & - & - & 3 & 22 \\
\hline $31-40$ & 13 & - & - & 1 & 1 & - & 2 & 17 \\
\hline $41-50$ & 9 & 4 & - & - & 1 & - & - & 14 \\
\hline $51-60$ & 4 & 7 & - & - & - & 1 & 5 & 17 \\
\hline $61-70$ & 4 & 4 & - & 1 & 1 & - & - & 10 \\
\hline 71 and $>$ & 1 & 2 & - & 1 & - & - & - & 4 \\
\hline Total & 74 & 19 & 4 & 3 & 3 & 3 & 13 & 119 \\
\% of Total & 62.2 & 16.0 & 3.4 & 2.5 & 2.5 & 2.5 & 10.9 & 100 \\
\hline
\end{tabular}

Note:

Trauma - Haemorrhagic necrosis from traumatic laceration

$\mathrm{HM}$ - Haematological malignancies

SCD - Sickle cell disease

MOS - Malignancy of other sites

ITSS - Immune tropical splenomegaly syndrome 
Fig 3: Cut surface of the spleen showing areas of haemorrhage and necrosis.

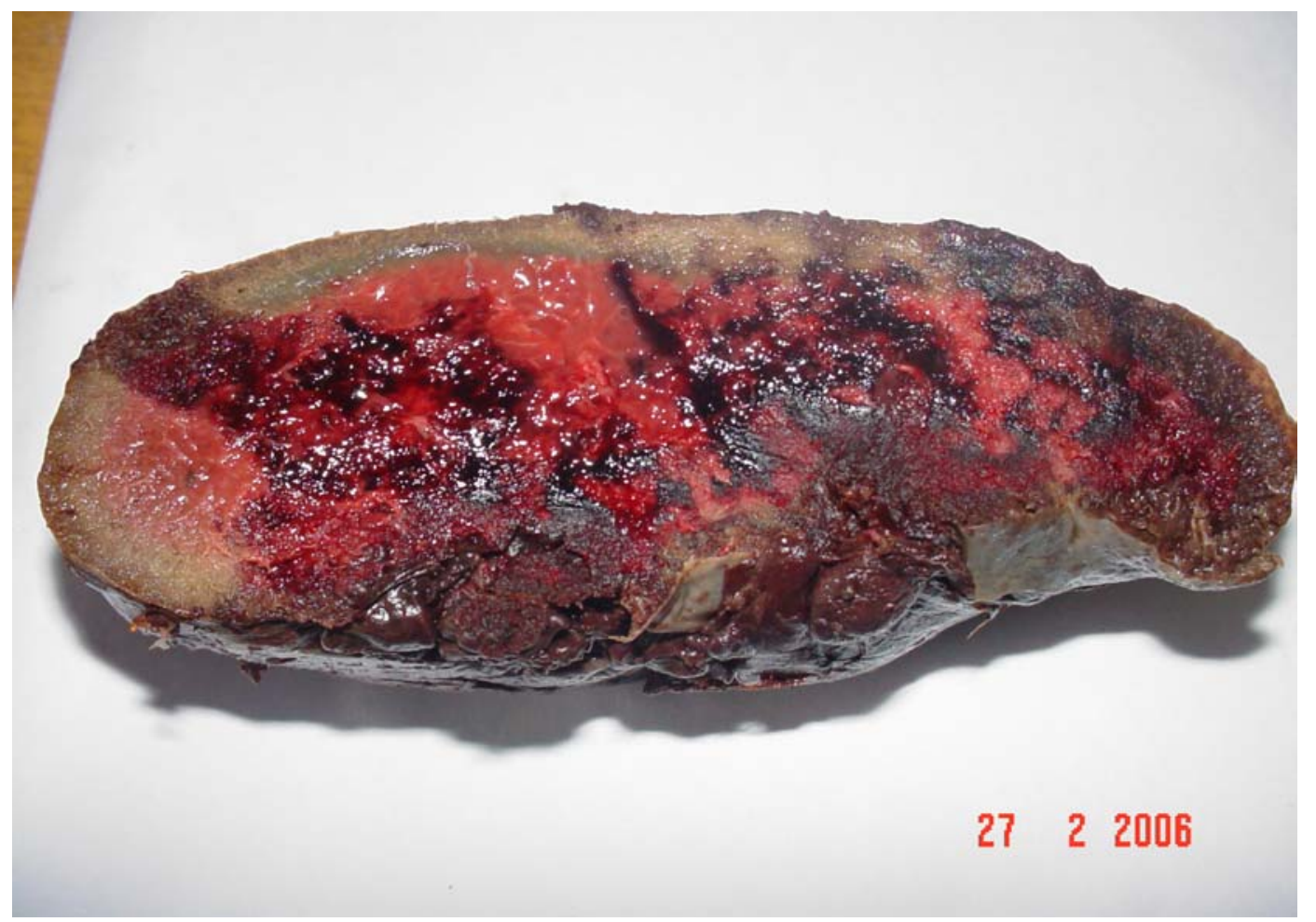

\section{Discussion}

Histopathological studies on the spleen in African blacks generally are not common. This paper reports on the pathological findings in 119 spleen specimens received at the Obafemi Awolowo University Hospital in Ile-Ife, Nigeria over a period of 18 years. This gives an average annual rate of six to seven. As far as we know this is the first study on the spleen in the last 30 years in Nigerians. Compared with the study of Jai et al at a Casablanca hospital where 70 splenectomies for haematological malignancies were done over a period of 6 years, the rate of splenectomy for haematological malignancies in this study is not high. All the spleens in this study were removed by the technique of open laparotomy. The indications for, and the advantages of laparoscopic splenectomy have been reviewed by Silecchia et al. [5] Laparoscopic splenectomy is presently not done in Nigeria. The technique is not suitable for large spleens, which is the case with many of the diseased spleen encountered in our study. Because the diagnosis was already known in most cases before splenectomy, it is not surprising that the correlation between the indication for splenectomy and the pathological findings was good. However, the handling of spleen specimens in the laboratory is inadequate. This is evidenced by the fact that only
$26.9 \%$ of the spleens had their weight recorded and only $71.4 \%$ had their dimensions recorded. Moreover, the presence or absence of malaria parasite on histology was not specifically mentioned in a country endemic for malaria infection.

The most common pathological finding in this study is haemorrhagic necrosis as a result of splenic laceration in RTA. Studies from different parts of Nigeria have shown that RTA is the most common cause of traumatic death [6-7] accidental death [8] as well as death due to surgical emergencies [9]. In all these and similar reports, abdominal injury with splenic damage was very common both in children as well as in adults $[10,11]$. In the report of Chinakwana et al [12] in Eastern part of Nigeria, RTA accounted for the second most common emergency operation after acute appendicitis. Smith et al in Liverpool [13] and Sayes et al in Birmingham [14], both in the United Kingdom reported RTA as the main cause of abdominal trauma in their studies. In both series, the liver was the most frequently injured abdominal organ, closely followed by the spleen. Several factors may contribute to this high rate of splenic damage as well as to the high rate RTA. Malaria and other infections in the tropics can cause chronic antigen stimulation and some degree of splenic enlargement with the tendency to rupture even on the application of a mild force. The fact that 
the spleen is largely unprotected by the ribs, particularly when it enlarges also makes it more susceptible to damage. Bad roads, driving under the influence of alcohol, inability to enforce highway codes such as speed limits, driving of badly maintained, rickety vehicles and probably some other factors may account for the high rate of RTA in Nigeria. The anatomic, unprotected feature of the spleen within the abdomen may be the reason for its frequent trauma in RTA in the United Kingdom and other countries where highway codes are strictly enforced.

Haematological malignancies predominantly CLL was the second most frequent finding in the spleen. Okany et al. [15] in Lagos noted that patients presented with more massive splenomegaly and at a lower peak age incidence (20-40 years) when compared with Caucasians. Splenectomy in CLL is part of tumour de-bulking and it reduces the disease stage to 2. Hypersplenism as well as pressure effect of a huge mass on the individual are also possible indications for splenectomy. The peak incidence of splenectomy for HM in this study (51-60 years) is slightly at variance with the findings of Okany et al [15] although we do know how many had splenectomy in Okany's series and at what age. Williams et al.16] in Ibadan, also in Nigeria compared the incidence rates for the leukaemia subtypes in Ibadan subjects with those of black and white Americans and found no striking difference in chronic myeloid leukaemia for the three population groups.

Another notable finding in this study is ITSS. In a study done thirty years ago in northern Nigeria, Bryceson et al. [17] reported ITSS to be the commonest cause of splenomegaly, and it was predominant among female cattle herders. The finding of ITSS solely among females in this study agrees with the findings of Bryceson et al., though none of the females with ITSS in our study was a cattle herder.

\section{Conclusion}

This study shows that most spleen specimens seen in our hospital are adequately examined both grossly and histologically. The absence of spleen weight, presence or absence of malaria parasite fibrosis in most of our reports is not good enough. Most spleens are removed for trauma related to RTA. Such spleen would show gross and microscopic features of splenic laceration or rupture. Chronic lymphocytic leukaemia is the most common haematological disease in splenectomy biopsies. The incidence of RTA has to reduce for the rate of splenectomy to decline. For this to happen there must be good roads, strict obedience of the highway codes and penalty for offenders. There is need also to pay more attention to the gross and microscopic description of the spleen.

\section{References}

1. Aster JC. Diseases of white blood cells, lymph nodes, spleen and thymus. In: Kumar V, Abbas AK, Fausto M. (Eds) Robbins and Cotran Pathologic basis of disease. Elsevier Saunders, Philadelphia, $7^{\text {th }}$ Ed. 2005: Pp661709.

2. Ameh EA, Chirdan LB, Nmadu PT. Blunt abdominal trauma in children: epidemiology, management, and management problems in a developing country. Paediatric Surgery International. 2000; 16:505-509.

3. Pugliese R, Maggioni D, Scandroglio I, Sansonna F, Grilloa G, DiLernia S, Ferran GC, Boniardi M, Costanzi A, Magistro C. Splenectomy in haematologic diseases. Clinical indications and surgical techniques. Chirugia Italiana. 2005; 57: 283-291.

4. Jai SR, Benamar MY, Benjelloun N, Kafir M, Fadil A, Alaoui BM, Zeroruali NO, Benchakroun H, Quessar A, Benchakroun S. Splenectomy in haematologic diseases. A study of 70 cases. La Tunis Medicale. 2005; 83: 326-330.

5. Silecchia G, Raparelli L, Casella G, Basso N. Laparoscopic splenectomy for non-traumatic diseases. Minerva Chirugica. 2005; 60: 363374.

6. Ehikhamenor EE, Ojo MA. Comparative analysis of traumatic deaths in Nigeria. Prehospital and Disaster Medicine. 2005; 20: 197-201.

7. Solagberu BA, Adekanye AO, Ofoegbu CP, Udofia US, Abdur-Rahman LO, Taiwo JO. Epidemiology of trauma deaths. West African Journal of Medicine. 2003; 22: 177-181.

8. Amakiri $\mathrm{CN}$, Akang EE, Aghadiuno PU, Odesanmi WO. A prospective study of coroner's autopsies in University College Hospital, Ibadan, Nigeria. Medicine Science and the Law. 1997; 37:69-75.

9. Ekere AU, Yellowe BE, Umune S. Surgical mortality in the emergency room. International Orthopaedics. 2004; 28:187-190.

10. Nwabunike T. Closed and penetrating abdominal injuries in Nigerian Igbos. Injury 1984; 15:372-375.

11. Adejuyigbe O, Aderounmu AO, Adelusola KA. Abdominal injuries in Nigerian children. 
Journal of the Royal College of Surgeons of Edinburgh. 1992; 37:29-33.

12. Chianakwana GU, Ihegihu CC, Okafor PI, Anyanwu SN, Mbonu OO. Adult surgical emergencies in a developing country: the experience of Nnamdi Azikiwe University Teaching Hospital, Nnewi, Anambra State, Nigeria. World Journal of Surgery. 2005; 29: 804-807.

13. Smith J, Caldwell E, D'Amours S, Jalaludin B, Sugrue M. Abdominal trauma: a disease in evolution. ANZ Journal of Surgery. 2005; 75:790-794.

14. Sayers RD, Bewes PC, Porter KM. Emergency laparotomy for abdominal trauma. Injury 1992; 23:537-541.

15. Okany CC, Akinyanju OO. Chronic leukaemia: an African experience. Medical Oncology and Tumour Pharmacotherapy. 1989; 6:189-194.

16. Oladipupo Williams CK, Bamgboye EA. Estimation of incidence of human leukaemia subtypes in an urban African population. Oncology. 1983; 40:381-386.

17. Bryceson AD, Fleming AF, Edington GM. Splenomegaly in Northern Nigeria. Acta Tropica. 1976; 33:185-214. 